\title{
ON THE EXISTENCE OF PERIODIC SOLUTIONS FOR A $p$-LAPLACIAN NEUTRAL FUNCTIONAL DIFFERENTIAL EQUATION WITH TIME-VARYING OPERATOR
}

\section{ZHENGXIN WANG, JiNDE CAO AND SHIPING LU}

Abstract. In this paper, a kind of $p$-Laplacian neutral functional differential equation with timevarying operator as follows

$$
\left(\varphi_{p}\left(u^{\prime}(t)-\sum_{i=1}^{n} c_{i}(t) u^{\prime}\left(t-r_{i}\right)\right)\right)^{\prime}=f\left(u^{\prime}(t)\right)+\beta(t) g(u(t-\gamma(t)))+e(t),
$$

is studied and some new results are obtained. It is worth noting that the parameters $c_{i}(t)(i=$ $1,2, \cdots, n)$ are functions and the coefficient $\beta(t)$ (which is ahead of $g$ ) is sign-variable here. It is interesting, but it is so challenging and difficult that few people have discussed it so far.

Mathematics subject classification (2010): 34K13, 47B39.

Keywords and phrases: time-varying operator, periodic solutions, neutral functional differential equation, Mawhin's continuation theorem, sign-variable.

\section{REFERENCES}

[1] W.S. Cheung And J. Ren, Periodic solutions for p-Laplacian Rayleigh equations, Nonlinear Anal., 65 (2006), 2003-2012.

[2] R.E. Gaines And J.L. Mawhin, Coincidence Degree and Nonlinear Differential Equations, Springer-Verlag, Berlin, 1977.

[3] F. LIANG, L. GUO AND S. LU, Existence of periodic solutions for a $p$-Laplacian neutral functional differential equation, Nonlinear Anal., 71 (2009), 427-436.

[4] S. LU, Existence of periodic solutions for a p-Laplacian neutral functional differential equation, Nonlinear Anal., 70 (2009), 231-243.

[5] S. Lu, W. Ge And Z. Zheng, Periodic solutions to neutral differential equation with deviating arguments, Appl. Math. Comput., 152 (2004), 17-27.

[6] S. LU AND Z. GUI, On the existence of periodic solutions to $p$-Laplacian Rayleigh differential equation with a delay, J. Math. Anal. Appl., 325 (2007), 685-702.

[7] K. WANG AND Y. ZHU, Periodic solutions for a higher order p-Laplacian neutral functional differential equation with a deviating argument, Nonlinear Anal., 71 (2009), 3906-3913.

[8] Z. WANG, S. LU AND J. CAO, Existence of periodic solutions for a $p$-Laplacian neutral functional differential equation with multiple variable parameters, Nonlinear Anal., 72 (2010), 734-747. 